\title{
Advanced hybrid closed-loop system: first successful clinical case after total pancreatectomy
}

\author{
A. Rizzi ${ }^{1} \cdot$ L. Tartaglione ${ }^{1} \cdot$ M. Di Leo ${ }^{1} \cdot$ S. Alfieri ${ }^{2} \cdot$ D. Pitocco ${ }^{1}$
}

Received: 21 February 2021 / Accepted: 30 March 2021 / Published online: 16 April 2021

(c) The Author(s) 2021

\section{Main Text}

A 64-year-old woman has undergone in February 2019 total spleen-preserving pancreatectomy for cystic pancreatic neoplasia. In her medical history, in 2010 she also underwent total thyroidectomy because of thyroid cancer. She is a former smoker who quitted smoking in 2014. From February 2019, she assumes pancrelipase 10.000 UI daily as pancreatic replacement therapy and from 2010 levotiroxine for thyroid replacement.

At the discharge, insulin therapy with multiple daily injections, supported by advanced educational therapeutic plan about carbohydrates counting, was started, but, after a severe hypoglycemic event, she developed an important fear of hypoglycemia with a consequent wrong approach to the insulin therapy, preferring to maintain glycemic values higher than $200 \mathrm{mg} / \mathrm{dL}$ in order to avoid hypoglycemia. Insulin therapy with continuous subcutaneous insulin infusion (CSII) was suggested, but she refused mainly because of discomfort. Yearly mean glycated hemoglobin (HbA1c) was $74 \mathrm{mmol} / \mathrm{mol}(8.9 \%)$. In December 2019, she was admitted to emergency room because of another severe hypoglycemia with loss of consciousness due to inappropriate insulin administration. After this event, patient started real-time continuous glucose monitoring (CGM-Medtronic Guardian Connect, Northridge California).

Managed by Antonio Secchi.

A. Rizzi and L. Tartaglione equally contributed to the manuscript.

D. Pitocco

dario.pitocco@policlinicogemelli.it

1 Diabetes Care Unit, Catholic University, Universitario Agostino Gemelli, L.Go Agostino Gemelli, 800168 PoliclinicoRome, Italy

2 Surgery Department, Catholic University, Universitario Agostino Gemelli, PoliclinicoRome, Italy
The examination of CGM data let her more aware of her glycemic patterns and their high variability. Therefore, in November 2020, she accepted to start CSII (Medtronic MiniMed 780G, Northridge California). At time of CSII initiation, she was $1.68 \mathrm{~m}$ tall, her weight was $57 \mathrm{~kg}$, with BMI $20.4 \mathrm{~kg} / \mathrm{m}^{2}$. She did not present any signs of malabsorption, diarrhoea or weight loss. In conjunction with hypoglycemia, she was educated to eat $15 \mathrm{~g}$ of carbohydrates and to check glycemia after 15 min until she recovered from the episodes. After initial training, she started CSII on Manual Mode, switching to Auto Mode (AM) 15 days later, with glycemic target set on $110 \mathrm{mg} / \mathrm{dL}$. Figure 1 resumes improvements of CGM metrics after 1 month in AM: there was an increase in time in range (TIR, $70-180 \mathrm{mg} / \mathrm{dl}$ ) from 43 to $69 \%$, almost achieving the goal suggested by the Advanced Technologies \& Treatments for Diabetes (ATTD) Consensus on CGM; time above range (TAR) decreased from 55 to $28 \%$, without increasing time below range, which does not reach the suggested $4 \%$ limit. No level 2 hypoglycemic episodes $(<54 \mathrm{mg} / \mathrm{dl})$ were recorded [1]. These results could also be compared with previous CGM data, when she presented TIR 28\% and TAR 72\% (25\% in level 1 and $47 \%$ in level 2). Improvement was also confirmed by $\mathrm{HbA} 1 \mathrm{c}$ that decreased to $58 \mathrm{mmol} / \mathrm{mol}(7.5 \%)$. We can detect a slight increase in coefficient of variation, switching from $37 \%$ up to $40 \%$. As notable in Fig. 1, in the first 2 weeks patient did not use bolus calculator but preferred to manually calculate boluses. The registered I:CHO was 1:10, as used on MDI. After the first 2 weeks, I:CHO was changed accordingly because of rapid decreasing glycemic after lunch and dinner, while increased for breakfast because of different quality of carbohydrates taken (higher glycemic index). We further changed the time of active insulin in the following weeks (Figure not available). Furthermore, in the CGM-only period she did not registered any other information rather than glycemic values.

In diabetes secondary to pancreatectomy, usually referred as T3cDM, insulin therapy management is highly 
Valutazione e progressi

(A) $10 / 05 / 2020$ - 20/05/2020 (11 giomi) (B) Non disponibilie

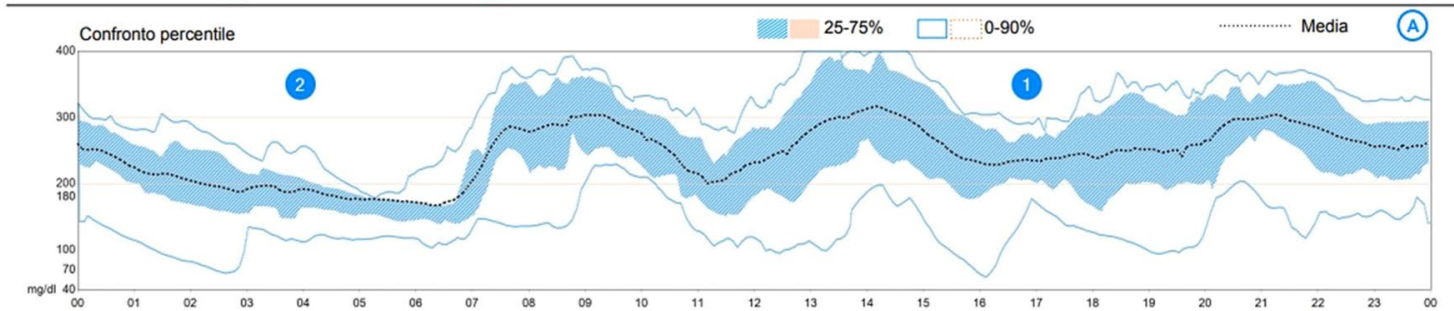

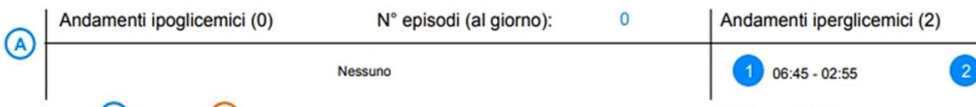

$\mathbf{N}^{\circ}$ episodi (al giorno): $\quad 0,2$

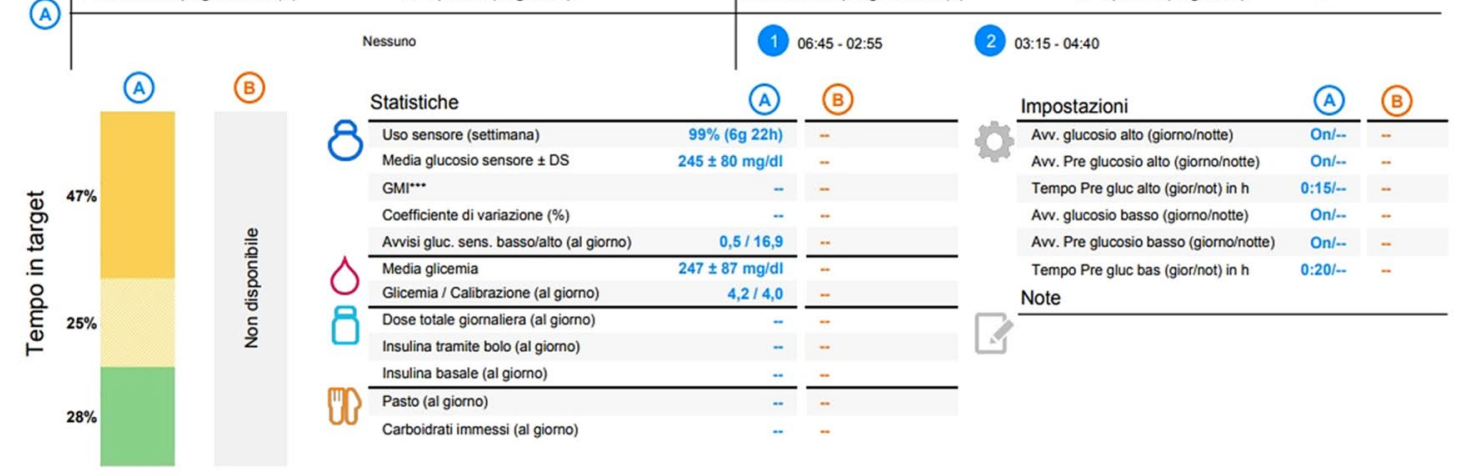

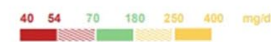

-.. Glucose Maragementi indicatiox

Valutazione e progressi

A) $25 / 12 / 2020$ - 07/01/2021 (14 giomi) (B) 24/11/2020 - 07/12/2020 (14 glorni)

Dati tratti da: Minimed 7806
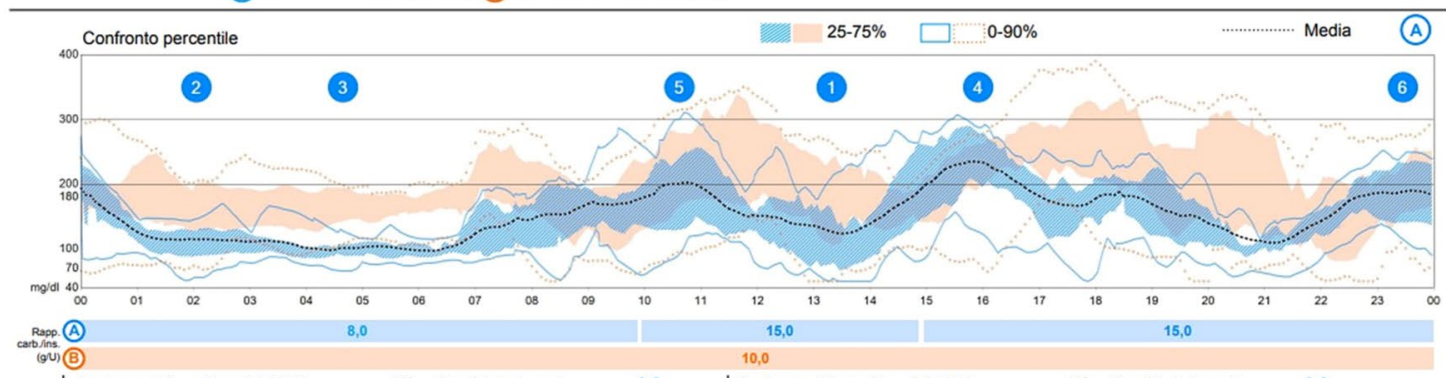

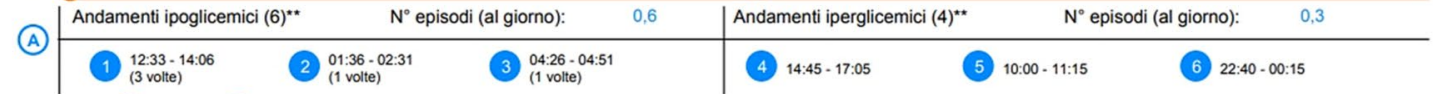

(A)

(B)

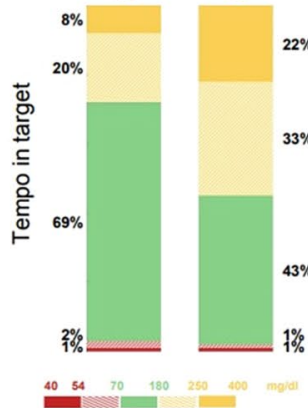

\begin{tabular}{l} 
Uscita da SmartGuard \\
\hline Nessuna calibrazione \\
Erogazione max SmartGuard \\
Erogazione min SmartGuard \\
Glicemia necessaria per \\
SmartGuard \\
Valore sensore poco accurato \\
Aggiornam. sensore \\
Nessun valore sensore \\
Fine sensore \\
SmartGuard disattivata dallutente \\
Sospensione prolungata \\
Periodo attesa SmartGuard \\
Causa non identificata
\end{tabular}

(A)

(B)

Statistiche

(A) (B)

\begin{tabular}{lrlll}
\hline SmartGuard (settimana) & $100 \%(7 \mathrm{~g} \mathrm{00h})$ & & $0 \%(00 \mathrm{~h})$ \\
Modalità manuale (settimana) & $0 \%(00 \mathrm{~h})$ & & $100 \%(7 \mathrm{~g} \mathrm{00h})$
\end{tabular} Uso sensore (settimana) $\quad 92 \%(6 \mathrm{~g} 10 \mathrm{~h}) \quad 98 \%(6 \mathrm{~g} 20 \mathrm{~h})$ Media glucosio sensore \pm DS $\quad 150 \pm 61 \mathrm{mg} / \mathrm{dl} \quad 194 \pm 72 \mathrm{mg} / \mathrm{dl}$ \begin{tabular}{lll} 
GMI $\cdots . \cdots$ & $6,9 \%$ & $8,0 \%$ \\
\hline
\end{tabular} Coefficiente di variazione (\%) $\begin{array}{lll}\text { Avvisi gluc. sens. basso/alto (al giorno) } \quad 5,1 / 3,2 & 2,8 / 8,2\end{array}$

$147 \pm 64 \mathrm{mg} / \mathrm{dl} \quad \frac{2,3 / 8,2}{212 \pm 88 \mathrm{mg} / \mathrm{dl}}$

Glicemia / Calibrazione (al giomo) $\quad 3,3 / 3,3 \quad 3,6 / 3,5$

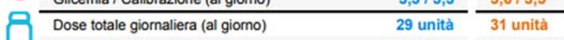
Insulina tramite bolo (al giorno) $\quad 18 \mathrm{U}(60 \%) \quad 24 \mathrm{U}(78 \%)$ Quantità correzione auto (al giorno) Insul. Basale Auto/Basale (al giorno) $5 \mathrm{U}(28 \%)$ 12U (40\%) $7 \mathrm{U}(22 \%)$ Sostituzione set Ogni 2,6 giorni Ogni 2,6 giomi Sostituzione serbatoio Ogni 2,8 giorni Ogni 2,8 giorni 
4Fig. 1 Subject's continuous glucose monitoring (CGM) graphics on MDI (upper light blue) and on sensor-augmented pump therapy (Auto Mode in blue and Manual Mode in orange). On the bottom-left CGM ranges of period in Auto Mode (column A) and period in Manual Mode (column B)

challenging because of the high risk of severe hypoglycemic episodes. There are not specific guidelines, but targets used for T1DM and T2DM are recommended, although higher glycemic values are often considered acceptable. In advanced cases, insulin pumps should be considered, exploiting carbohydrate counting and trend arrows [2]. Type 1 diabetes and pancreatectomy could seem similar conditions because of insulin deficiency, but they are very different mainly because of the absence of glucagon as consequence of total pancreatectomy. Niwano et al. demonstrated that in subjects with pancreatectomy basal insulin and total daily insulin requirements are lower compared to subjects with type 1 diabetes. For example, subjects with total pancreatectomy do not require to increase insulin infusion rate early in the morning as seen in T1DM [3]. A recent case-control study evaluated throughout CGM glycemic variability in subjects with pancreatectomy confirming higher mean plasma glucose values and higher $60 \mathrm{~min}$ CONGA, while coefficient of variation and standard deviations were comparable with HbA1c-matched subjects with T1DM [4]. Notably all subjects included in this study were on multiple daily injections, 7/10 on detemir twice daily and 3/10 on glargine (both $100 \mathrm{UI} / \mathrm{ml}$ and $300 \mathrm{UI} / \mathrm{ml}$ ). On MDI and CGM, our patient presented mean glucose value (247 mg/dl or $13.8 \mathrm{mmol} / \mathrm{l}$ ) and standard deviation $(87 \mathrm{mg} /$ $\mathrm{dl}$ or $4.9 \mathrm{mmol} / \mathrm{l}$ ) higher than those described by Juel et al. (respectively, $190 \mathrm{mg} / \mathrm{dl}$ or $10.6 \mathrm{mmol} / 1$ and $68 \mathrm{mg} / \mathrm{dl}$ or $3.8 \mathrm{mmol} / \mathrm{l})$. We chose to take advantage of advanced hybrid closed loop (AHCL) to improve mean glucose levels and minimize variability: in fact, in subjects with T1DM AHCL increased of $12.5 \%$ TIR, with greater improvement overnight [5].

AHCL allowed our patient to improve metabolic control and all the glycemic variability metrics. Even more, it let patient to gain confidence with the over-all system and especially with lower glycemic values, reducing the fear of hypoglycemia. Patient reported improvement of quality of life and the reduction in diabetes burden. The improvement of quality of life was not assessed by any specific test, but it was evaluated during visit: patient referred less anxiety in the management of diabetes and to feel more secure with glycemic fluctuations. Improvement of metabolic control has been confirmed at follow-up visit, after 3 months, when patient presented $69 \%$ of TIR in the 14 days before the visit and HbA1c level was 7.2\% (55 mmol/mol). Our case suggests how AHCL could be a successful approach in challenging subjects with T3cDM. In those subjects with long life-expectancy or good prognosis from an oncologic point of view after pancreatectomy, AHCL system, avoiding severe hypoglycemia and major hyperglycemic events and improving quality of life, should be considered also a costeffective option. Further studies and clinical trial should be designed to confirm and support our observations described in this clinical case.

Patient agreed to publish her case report and to publish figures of her CGM anonymously. She signed informed consent.

Funding Open access funding provided by Università Cattolica del Sacro Cuore within the CRUI-CARE Agreement.

\section{Compliance with Ethical Standards}

Conflict of interest Authors declare no conflicts of interest.

Informed consent All subjects signed informed consent before participation to the study. Study protocol and informed consent were approved by local Ethic Committee.

Open Access This article is licensed under a Creative Commons Attribution 4.0 International License, which permits use, sharing, adaptation, distribution and reproduction in any medium or format, as long as you give appropriate credit to the original author(s) and the source, provide a link to the Creative Commons licence, and indicate if changes were made. The images or other third party material in this article are included in the article's Creative Commons licence, unless indicated otherwise in a credit line to the material. If material is not included in the article's Creative Commons licence and your intended use is not permitted by statutory regulation or exceeds the permitted use, you will need to obtain permission directly from the copyright holder. To view a copy of this licence, visit http://creativecommons.org/licenses/by/4.0/.

\section{References}

1. Battelino T, Danne T, Bergenstal RM et al (2019) Clinical targets for continuous glucose monitoring data interpretation: recommendations from the International Consensus on time in range. Diabetes Care 42(8):1593-1603

2. Makuc J (2016) Management of pancreatogenic diabetes: challenges and solutions. Diabetes Metab Syndr Obes 25(9):311-315

3. Niwano F, Hiromine Y, Noso S et al (2018) Insulin deficiency with and without glucagon: a comparative study between total pancreatectomy and type 1 diabetes. J Diabetes Investig 9(5):1084-1090

4. Juel CTB, Dejgaard TF, Hansen CP et al (2021) Glycemic control and variability of diabetes secondary to total pancreatectomy assessed by continuous glucose monitoring. J Clin Endocrinol Metab 106(1):168-173

5. Collyns O, Meier R, Betts Z et al (2020) Improved glycemic outcomes with medtronic minimed advanced hybrid closed-loop delivery: results from a randomized crossover trial comparing automated insulin delivery with predictive low glucose suspend in people with Type 1 Diabetes. Diabetes 69(Supplement 1):199

Publisher's Note Springer Nature remains neutral with regard to jurisdictional claims in published maps and institutional affiliations. 